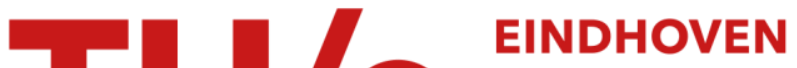 \\ UNIVERSITY OF \\ TECHNOLOGY
}

\section{Science, technology and society : a methodological perspective}

\section{Citation for published version (APA):}

Vries, de, M. J. (1997). Science, technology and society : a methodological perspective. In M. J. Vries, de, \& A. Tamir (Eds.), Shaping concepts of technology : from philosophical perspective to mental images (pp. 21-32). (International Journal of Technology and Design Education; Vol. 7(1-2)). Kluwer Academic Publishers. https://doi.org/10.1007/978-94-011-5598-4_3

DOI:

10.1007/978-94-011-5598-4_3

Document status and date:

Published: 01/01/1997

\section{Document Version:}

Publisher's PDF, also known as Version of Record (includes final page, issue and volume numbers)

\section{Please check the document version of this publication:}

- A submitted manuscript is the version of the article upon submission and before peer-review. There can be important differences between the submitted version and the official published version of record. People interested in the research are advised to contact the author for the final version of the publication, or visit the $\mathrm{DOI}$ to the publisher's website.

- The final author version and the galley proof are versions of the publication after peer review.

- The final published version features the final layout of the paper including the volume, issue and page numbers.

Link to publication

\section{General rights}

Copyright and moral rights for the publications made accessible in the public portal are retained by the authors and/or other copyright owners and it is a condition of accessing publications that users recognise and abide by the legal requirements associated with these rights.

- Users may download and print one copy of any publication from the public portal for the purpose of private study or research.

- You may not further distribute the material or use it for any profit-making activity or commercial gain

- You may freely distribute the URL identifying the publication in the public portal.

If the publication is distributed under the terms of Article 25fa of the Dutch Copyright Act, indicated by the "Taverne" license above, please follow below link for the End User Agreement:

www.tue.nl/taverne

Take down policy

If you believe that this document breaches copyright please contact us at:

openaccess@tue.nl

providing details and we will investigate your claim. 


\title{
Science, Technology and Society: A Methodological Perspective
}

\author{
MARC J. DE VRIES \\ Eindhoven University of Technology, Eindhoven, the Netherlands
}

\begin{abstract}
Methodology offers a perspective on technology that differs from a historical or sociological one. It focuses on the scientific, technological and social factors that are to be taken into account in technological developments. Other approaches tend to focus on actors rather than factors. The (design) methodological approach is illustrated by the case study of the development Active Matrix Liquid Crystal Displays in a small Dutch company. It appears that problems emerge when this development is not dealt with according to the nature of the technologies that are involved. In technology education such insights can be used to prevent practices in which pupils are naively taught to work according to standardised design process prescriptions that do not take into account the nature of the product that is to be designed.
\end{abstract}

Keywords: design methodology, philosophy of technology, active matrix liquid crystal displays.

\section{THE METHODOLOGICAL PERSPECTIVE COMPARED WITH HISTORICAL AND SOCIOLOGICAL PERSPECTIVES}

Technological developments can be described from a variety of perspectives, e.g. historical, sociological or methodological. Methodology, strictly speaking, is the application of logic to practical situations. In the case of the methodology of technology these practical situations are the technological developments. A methodological perspective is particularly suitable for deriving insights into the relationships between science, technology and society from practical experiences.

In the past it was not unusual to limit the historical study of technology to purely technical aspects, i.e. the so-called internalist approach. A second approach is the externalist approach, whereby the social circumstances under which technological developments take place is central. Nowadays the second approach seems to be the more popular. In particular it focuses on the interaction between various social actors in technological developments. It has thus led to studies that combine the disciplines of history and sociology.

In the introduction to a well known collection of articles (Bijker, Hughes \& Pinch, 1989) we find the various strategies used in this type of studies. Hughes is representative of a 'systems' approach that sees technological developments as the result of cooperation between various organisations. Callon and Latour present studies in which the interaction between social actors ('actor-networks') play a vital role. In a number of other studies, structured according to the SCOT approach $(\mathrm{SCOT}=$ Social Construction 
Of Technology) the descriptions of technological developments are dominated by the social aspects. Well-known is the example of the historical development of the bicycle, as described by Bijker, that tries to show that this development is primarily influenced by the concept certain groups of people had of a bicycle (whether it is a transportation means or a macho device) rather than by the technical characteristics of the bicycle. This is not only speculative, but also not of much use for those who are involved in the development of products. They can only manipulate the technical characteristics of the product, carefully watching their customers' expectations, but they can not easily influence the customers' concept of their products. Also, they can not easily influence the interactions between the social actors which plays such a vital role in the SCOT analysis of technological innovation (also see the chapter in this book by K.-H. Hansen).

There may be a legitimate place for socio-historical studies of technological developments in giving pupils an insight into the complex ways in which technological developments are influenced by social actors. But it is evident that from a practical point of view there is a need for a different perspective, which is more suitable for deriving information about how to make practical decisions in product development. The methodological perspective can serve as such an approach. Later in this chapter, a multifactorial approach to design methodology will be discussed. This approach does not focus on the actors (as e.g. in the SCOT approach), but on the factors that are involved in the development of products. This relieves us of the difficulties of trying to predict the behaviour of actors, which is partially guided by rationality, but also by other, psychological factors. It limits the analyses to observable phenomena, which are already difficult enough to identify and describe.

\section{FROM 'PHILOSOPHY OF TECHNOLOGY' TO 'DESIGN METHODOLOGY'}

The philosophy of technology, defined as a discipline reflecting on the nature and effects of technology, is no older than the mid 1950s. Mitcham (1994) distinguishes two types of scientific reflection on technology: one from an engineering point of view and the other from a humanities point of view. Although the names he uses ('philosophical technology' versus 'philosophy of technology') are questionable, he is able to make clear that the first approach (with which he associates Kapp, Dessauer, Espinas, Van Riessen, Schuurman and Bunge) is more involved with the nature of technology whereas the second approach (represented by e.g. Mumford, Ortega y Gasset, Heidegger and Ellul) puts a stronger emphasis on the effects of technology on humans and society. His claim, however, that the second approach is more inclusive than the first can be contested by looking at the way both scientific-technological and social factors are included in design methodology as a more exact and more focused type of a "philos- 
ophy of technology' from an engineering point of view. More exact, because methodology by its nature is less speculative and more based on logical considerations than philosophy, and more focused because it deals with design as the 'heart' or 'axis' of technology. It is this more exact and more focused character of design methodology that makes it so relevant for discussions of goals, needs and policies for technology education.

It should be noted that the psychology of design is not included in this approach. A study of the way designers think is certainly relevant to technology education and as we will see later, results from such studies sometimes confirm conclusions about technology education in a striking way.

\section{FOUR AREAS OF DESIGN METHODOLOGY}

Mitcham (1994) distinguishes four ways of defining 'technology': as objects, as knowledge, as activities and as volition (the will to survive, to control). These ways of defining technology seem to match well with the four areas of design methodology that were identified at the end of an international conference on 'Design Methodology and Relationship with Science', aimed at presenting a state-of-the-art description of design methodology as an academic discipline: teleology, epistemology, methodology (in the narrow sense of 'the study of methods') and ontology (De Vries, 1993i). A short description of each area now follows.

The first deals with the goal of designing: to make products that will be used by people. Research questions in this area focus on the way in which design can best match customers' requirements when using the products. As use is the only experience most people have of technology, they tend to see technology as a set of products. This has been found in studies both among pupils and adults (Mitcham, 1994, Raat et al., 1987). In design practice, a collection of methods is available now under the heading of total quality management. One of these methods relating customers' requirements to product specifications is Quality Function Deployment.

The second area deals with the different types of knowledge involved in designing products. Research in this area (Sarlemijn, 1993) has shown that it is necessary to distinguish three different types of technology: experience-based technologies, macro-technologies and micro-technologies. A study of categories of design knowledge and activities through which these types of knowledge are generated has been done by Vincenti (1990). As the epistemology of technology is the concern of other chapters in this publication (by Ropohl and Ihde), this area will not be dealt with in great length here.

The third area deals with a variety of design activities and the ways in which they are organised in design processes. Here, we find many studies of the value and limitations of step models for design processes. Observational studies have shown that designers in most cases do not stick 
to prescribed processes, but move through a series of activities in a rather flexible way.

The fourth area is the least developed according to, for example, Marzano, who gave the opening presentation at the design methodology conference mentioned above (De Vries, 1993i). It deals with the way designs add to the quality of life and the well being of people as they experience it. People have the will to survive and to a certain extent have control over their environment, and technology can offer a means of doing that.

To these four areas four types of goals and needs for technology education can be related (De Vries, 1993ii). These are skills in using the products of technology (first area) and in designing activities (third area), attitudes to do that in a critical way (fourth area), knowledge of technology (second area), and the development of a balanced concept of technology (second area).

\section{MULTIFACTORIAL ANALYSES IN DESIGN METHODOLOGY}

As stated before, design methodological analyses focus on the factors (i.e. observable phenomena) relevant to the development of a particular product. The following types of factors can be distinguished:

- scientific factors: the natural phenomena that underlie the functioning of a product,

- technological factors: factors like the availability of materials and production processes, that together describe a technical system,

- market factors: not only the number of possible customers, but also their requirements in terms of quality and functionality,

- political factors: political debates and decisions with respect to technological developments,

- juridical factors: laws, existing patents, but also quasi-juridical factors like technical norms and standards,

- aesthetic factors: feelings about the appearance of a product in terms of beauty or ugliness.

Research (Sarlemijn, 1993, De Vries, 1993iii, De Vries, 1994iii) has shown that the success or failure of product designs can be explained in terms of the extent to which management has been able to match the design with a combination of the various factors and to react to changes in these factors during the development process.

A CASE STUDY: THE DESIGN OF ACTIVE MATRIX LIQUID CRYSTAL DISPLAYS (AMLCDS)

To show the practical relevance of methodological analyses a case study is now presented. It will illustrate how a design methodological analysis can yield practical implications for design strategy and policy. At a simplified 
level the same type of analyses can give pupils and students a better understanding of the complexity of product design.

The focus of the case study is a new type of television display: active matrix liquid crystal displays (LCDs). These displays are very flat and can be used in situations where there is not much space for a display. Examples of such situations are screens in notebook computers, television screens in the back of airplane seats, and viewfinders in camcorders. These screens are based on the following principle (Kaneko, 1987, Howard, 1992).

Between two parallel flat glass plates, separated from each other by little plastic balls called 'spacers', one inserts a layer of long stretched polymer molecules (the liquid crystal). Both plates are covered with a conducting and transparent layer of indium tin oxide (ITO). By rubbing the glass plates the molecules close to the plates will be forced in one direction. The direction of rubbing in the upper plate is perpendicular to the rubbing direction in the lower plate. The orientation of the molecules changes gradually from one plate to the other. This has a consequence for the optical properties of the display. On both glass plates a polarising filter is applied, such that the direction of polarisation is the same as the orientation of the molecules. Light, coming from the backlighting (TL) that hits one glass plate, is polarised and on its way through the display the twist in orientation of the molecules also twists the direction of polarisation of the light. In this situation the light can pass through the display. When, however, an electrical field is applied to a pixel in the display, the orientation of the molecules becomes perpendicular to the glass plates. In this situation the polarisation orientation is no longer twisted by the molecules and the light can no longer pass the second plate. This causes the pixel to become dark.

There are two types of LCDs. The older type are the passive matrix LCDs. In those displays the electrical field is applied row by row. They can be found mainly in black-and-white television applications (such as the displays of digital watches and measuring instruments). In active matrix LCDs (AMLCDs) each pixel has its own individual electrical switch.

Active matrix LCDs are better for colour television. For colour screens, each pixel has to be coloured in some way. Several processes have been developed to accomplish this. There are different ways of applying the electrical signal to the pixels. With most displays transistors that are applied on the glass plate as a small layer (hence the term Thin Film Transistors) serve as the switches. The plate on which the transistors are damped is called the active plate; the other plate is called the passive plate. The applying is done by using masks. For each layer of the transistor, the plate with photosensitive material is lit while a mask is put on top. The alternative method for switching the signal is to use diodes. In this case the production of the passive plate becomes more complex because it too has to be structured (with transistors only the active plate is structured). On the other hand, diodes need less mask steps to be applied on the plate.

The case study focuses on the way a small business corporation in the 
Netherlands - the name of which is not given here for reasons of confidentiality - worked on the development of AMLCDs since 1987. This process was described by Broekaart, who works for this company. He identified the major decisions in the period 1987-1993 and analysed how scientific, technological, market, political, juridical and aesthetic factors were taken into account or ignored in the management decisions.

Among other things the development of AMLCDs requires knowledge of the behaviour of the polymer molecules. Therefore, one might expect a microtechnological approach to be appropriate here. Previous case studies have shown that in such an approach attention usually concentrates at first on the scientific and technological factors and only later is there a more concrete market focus, whereby political and juridical considerations also become relevant. Broekaart, however, found that the pattern in the AMLCD case differed from this and he noticed that this was one of the causes of problems in the development sequence.

In July 1987, a decision was taken by the company to undertake a feasibility study for AMLCDs. There were indications that there would be a market for 6 inch colour screens. At that time the largest commercially produced screens were 3 inch (this was a growing market), but they were found to be rather small for entertainment purposes. No direct market research was done, because the LCDs would be produced for Philips Consumer Electronics and they were responsible for the total product (e.g. the television) and its marketing. The choice was made to work with diode switches for the LCD, although until then all Japanese companies leaders in this field since 1985 - used transistors. The company, however, had more experience with diode technology. It was expected that the experience in the colouring process could be derived from the experience in producing traditional Cathode Ray Tube (CRT) colour screens. Thus, both technological and market factors were taken into consideration, although there was more speculation than well based evidence about their nature. No political or juridical factors seemed to be relevant at that time and no need for fundamental research was identified.

In October 1987 there was still uncertainty about the colouring process that would be used. Many options were tried out simultaneously, which because of the limited capacity could not yield good results. This research had a trial-and-error character not found in more fundamental research. In addition options were kept open, like buying colour filters from Japanese companies or working with a partner who would develop the colouring process. Because of these options one became aware of the need to study the role of patents in developing the AMLCDs.

In April 1988 no choice had still been made. To the contrary, it was decided to add new options to those already studied. Also, it was decided to at least start with bought filters and - it was hoped - gradually take up in-house production of the filters later on. From now on, the choice of materials was sometimes limited by environmental considerations, though often one was forced to choose a polluting material because of a lack of suitable 
alternatives. LCDs produced in Japan were analysed to gain an insight into the production processes that had been used there. A decision was taken to apply the colour filter under the ITO layer instead of on top of it. As with the choice for diodes, this again meant a deviation from the standards that were used in Japan. Meanwhile there was a shift in the market: the quality difference between passive and active matrix LCDs has decreased and there was a trend towards larger screens. However, this shift did not play a role in the decision making at that time.

In December 1988 a decision was taken to start a pilot production based on one of the available dye processes for colouring the pixels. In the view of management this, however, did not mean that the same technique would also be used for mass production. In addition part of the colour filters had to be bought as long as the production yield remained too low. The shift towards larger screens became more evident as the Japanese companies brought out commercial versions of 4 and 6 inch screens. The pilot production of the company we study, however, was first for 3 to 4 inch screens (one is not yet able to produce larger screens oneself). Via Philips there seemed to be a client: the AMLCDs would be built into the back of Boeing 747 airplane seats.

In September 1989 a number of production problems, in particular with the so-called passivation layer that protects the display from external influences, was identified, but no fundamental research to gain insight into the causes of these problems was initiated. Instead, one more and more became dependent on buying filters from Japanese manufacturers. As the filters were produced specially for the unusual glass size that was required, the prices paid for the filters were very high. The strategy was still based on direct view television, while a new development, projection television for which Sharp had already brought out an AMLCD, was ignored. IBM and Toshiba had started working on 10 inch colour screens for computers. It was expected that AMLCDs would get a more prominent place in laptops and notebook computers since they were the best option for colour screens in these applications.

In June 1990 not a single self produced AMLCD of sufficient quality had yet come out of the pilot factory. It was decided that the mass production would be on the basis of bought colour filters, even though at that time the suppliers already had difficulties with the large numbers of the filters that were ordered. A number of optional processes for in-house production were still maintained. The choice of these processes changed during the product development. The ideal process had still not been identified. To prevent too large a loss of confidence a commitment was made to produce 100 six-inch screens within a year. A growth in the market for colour LCD television was still expected, even though Sharp was convinced that the major market growth would be in the office sector (notebooks, desktops).

In July 1991 a breakthrough was made. Some fundamental research on a number of the production problems had finally been done. In particular 
the adhesion problem (layers that become loose after they have been applied on the glass) had been solved. Soon after, it proved possible to produce a constant flow of LCDs of sufficient quality. Some problems still remained, for which again no fundamental research was started. Although all competitors had already shifted their strategy towards data graphic screens (in computers), the management still stuck with direct view colour television. Changes in the options for the colour filter production process were kept open as was the choice of filter suppliers.

In December 1991 the formal decision to start mass production was taken. The target was still six-inch screens and it was still unclear who would supply a sufficient number of colour filters (it was decided that only $25 \%$ of the filters would be produced in-house). A change was made from a dye to a pigment process, but several other options were kept open. It became increasingly evident that patents might become a problem. In this rapidly developing field the patent situation was constantly unclear and the possibility of sudden claims by patent holders had to be kept in mind all the time.

In June 1992 it was finally decided to follow the market trend and shift towards data graphic screens, first in black-and-white with the hope that soon afterwards colour screens for data graphic purposes could be produced. It was also decided to make more use of fundamental research to solve the remaining production problems (e.g. the still unexplained so-called 'cauliflower' problem).

The last decision that has been analysed relates to August 1993. The results of fundamental research were by that time already yielding the first improvements in production. A definite choice for a pigment colouring process was made. Based on market research it was decided to try to bring out colour LCDs earlier than had been planned in June 1992.

Recent observations show that the yield of the production process has improved substantially because the main production problems were solved, not least as a result of fundamental research.

Looking back at the whole process we can conclude the following.

1. The role of fundamental research was underestimated by the management for a long time. That such research is important could have been expected by realising that both the working and the production of AMLCDs are based on atomic level phenomena. Therefore a microtechnological approach can be expected to be more suitable than one derived from experience or based a macrotechnological approach.

2. The focus was kept on technological factors exclusively during almost the whole process. Too many options were kept open for too long. As a result one was not able to make a sufficiently detailed study of the technological factors. The attention was divided over too many techniques.

3. Market developments were neglected for a long period. The process started with an awareness of what the market might be, but after that, attention was diverted from later developments, even when the impor- 
tant decision for mass production was taken. Fortunately this decision was changed before the real mass production began.

4. Juridical factors have been unclear because of the newness of the product and the rapidity of developments. This is typical of a microtechnological development, where the product has no clear precursor from which the possible content of patents can be derived.

5. From the beginning, environmental requirements as a political factor were taken into account. However the relevance of these factors was only marginal. In some cases, the choice of certain materials was limited by the fact that some materials were environmentally unfriendly. But often it was necessary to choose a material that was only a little less dangerous, simply because there were no alternatives. The production process therefore remains a 'dirty' process in many respects.

What we learn from this case study is that no factor can be neglected without risk. The relative importance of the facts should be adapted to the nature of the technology (in this case a microtechnology, in which scientific factors play a vital role, as the company found out after ignoring them for a considerable period). Change in the relevant factors needs to be monitored throughout the process. Market shifts should be taken into account. This requires a certain level of flexibility in the development process. One should not rigidly stick to choices that have once been made, just because the basis for those decisions was good at that time. This basis may be absent later due to changes in other factors.

\section{IMPLICATIONS FOR TECHNOLOGY EDUCATION}

The aim of this chapter is to make clear how a (design) methodological perspective on the relationships between science, technology and society can be valuable in presenting elements for establishing the goals, needs and policies for technology education on the basis of empirical studies of technological developments. We have seen an example of such a study as an illustration of certain concepts and theories in design methodology. It will be evident that this type of analysis is quite different from a historical or sociological approach. We did not aim for a complete historical description of all facts related to the development of the AMLCD. Instead a number of facts was selected and we looked at the way they influenced the design process. Nor did we search for all interactions between the various actors that were involved: the Philips divisions, the Japanese colour filter suppliers, the customers, and the AMLCD developing Dutch company. We did consider all these actors but not in terms of their (unpredictable and often irrational) behaviour but only in terms of the phenomena they caused (the creation of new knowledge about AMLCDs, the availability of necessary technologies and supplies, the establishment of norms and standards in screen sizes, restrictions due to the existence of patents, etc.). What conclusions can we draw from such analyses and how can they be useful to 
technology educators as a contribution to the academic foundations of technology education?

First we see the need to bring together scientific, technological and social knowledge. In terms of school subjects this implies cooperation and coordination of different disciplines (some even go further and make a plea for integration). This is not new and has been stated many times before, but design methodological analyses give a practical content to this linking of school subjects. It helps us to avoid naïve 'technology is applied science' approaches as we have seen in some science education and STS education projects, as I have described elsewhere (De Vries, 1994i). In the AMLCD case, the role of fundamental scientific research was important. We should realise that in other cases (in particular of experience based technologies) this role can be quite different. This will be reflected in technology education: we should not try to relate design projects to science education in all cases. In fact, those cases in which the role of science is most prominent (in microtechnologies) are the most difficult ones to deal with in education because of the often highly abstract physics concepts they require and which are not dealt with in science education until upper secondary education.

Secondly, the AMLCD case study shows us that step models for design processes are not always recognisable in practice. It is almost impossible to distinguish 'determination of list of requirements', 'coming up with possible solutions', 'elaborating a chosen solution' as separate steps in this process. The process looks more 'chaotic' because it has to follow changes in the scientific, technological and social factors that influence it. Here, too, we should realise that this can be different in other cases. In particular in the macrotechnological design processes involved in mechanical engineering these processes are often well structured according to classical models, like that by Pahl and Beitz (1988) (also see (Roozenburg and Eekels, 1995)). But in other types of technologies the design process can hardly be described efficiently in this way. This should make us careful about requiring pupils and students to use standard step models in all design assignments and formulate 'general design skills' as a goal in technology education without mentioning the important relationships with knowledge of technological concepts. Design processes should be adapted according to the type of product they are applied to. Designing AMLCDs is done in a different way from designing corkscrews. This reality should be taken into account in technology education (also see McCormick, 1993 and McCormick et al., 1994, who reaches the same conclusion but from a pedagogical point of view).

Thirdly the AMLCD case study has shown us the complexity which modern business companies face when designing new products. Of course, it can not be the goal of technology education to confront pupils with this full complexity. Education almost by definition means simplifying. And yet, we should be careful not to make a false impression of simplicity when dealing with the teaching of technological developments. Starting with only 
a few factors and gradually adding more and different types of factors, pupils should learn to integrate scientific, technological and social factors into their design projects (De Vries, 1994ii). In this way their insight into the complexity mentioned above will grow as they move through the technology education curriculum.

\section{REFERENCES}

Bijker, W. E., Hughes, T. P. \& Pinch, T. (eds.): 1989, The Social Construction of Technological Systems. New Directions in the Sociology and History of Technology, MIT Press, Cambridge, MA.

Broekaart, M.: 1994, Een ontwerpmethodologische studie naar het maken van een kleurfilterproces voor de AM-LCD's (A Design Methodological Study into the Development of a Colour Filter Process for AM-LCD's; unpublished M. Eng. thesis). Eindhoven University of Technology, Eindhoven.

Cross, N.: 1994, Engineering Design Methods. Strategies for Product Design, John Wiley \& Sons Ltd, Chichester.

Howard, W. E.: 1992, 'Thin-film-transistor/liquid Crystal Display Technology - An Introduction', IBM J. Res. Develop. 36(1), 3-10.

Kaneko, E.: 1987, Liquid Crystal TV Displays: Principles and Applications of Liquid Crystal Displays, KTK Scientific Publ./Reidel Publ. Comp, Tokyo/Dordrecht.

McCormick, R.: 1993, 'Design Education and Science: Practical Implications', in M. J. de Vries, N. Cross \& D. P. Grant (eds.): 1993, Design Methodology and Relationships with Science, Kluwer Academic Publishers, Dordrecht.

McCormick, R., Murphy, P. \& Henessy, S.: 1994, 'Problem-Solving Processes in Technology Education: A Pilot Study', International Journal of Technology and Design Education $4(1), 5-34$.

Mitcham, C.: 1994, Thinking Through Technology. The Path between Engineering and Philosophy, University of Chicago Press, Chicago.

Pahl, G. and Beitz, W.: 1988, Engineering Design: A Systematic Approach, Springer/The Design Council, Berlin/London.

Raat, J. H., Klerk Wolters, F. de \& Vries, M. J. de: 1987, Report PATT-Conference 1987, Vol. 1 Proceedings, University of Technology, Eindhoven.

Roozenburg, N. F. M. \& Eekels, J.: 1995, Product Design: Fundamentals and Methods, John Wiley \& Sons Ltd, Chichester.

Sarlemijn, A.: 1993, 'Designs are Cultural Alloys. STeMPJE in Design Methodology', in M. J. de Vries, N. Cross \& D. P. Grant (eds.), Design Methodology and Relationships with Science, Kluwer Academic Publishers, Dordrecht.

Staudenmaier, J. M.: 1989, Technology's Storytellers. Reweaving the Human Fabric, MIT Press, Cambridge, MA.

Vincenti, W. G.: 1990, What Engineers Know and How They Know It. Analytical Studies from Aeronautical History, John Hopkins University Press, Baltimore, Maryland.

Vries, M. J. de: 1993i, 'Design Methodology and Relationships with Science: Introduction', in M. J. de Vries, N. Cross \& D. P. Grant (eds.), Design Methodology and Relationships with Science, Kluwer Academic Publishers, Dordrecht.

Vries, M. J. de: 1993ii, 'Concept and Attitude Formation as a Goal in Technology Education', in J.-L. Martinand \& A. Durey (eds.), Actes du séminaire de didactique des disciplines technologiques - Cachan - 1992-1993, Université Paris VII, Paris.

Vries, M. J. de: 1993iii, 'The Philips Stirling Engine Development: A Historical-methodological Case Study into Design Process Dynamics', Methodology and Science 26, 74-86.

Vries, M. J. de: 1994i, 'Technology Education in Western Europe', in D. Layton (ed.), Innovations in Science and Technology Education, Vol. V, UNESCO, Paris. 
Vries, M. J. de: 1994ii, 'Design Methodological Analyses as a Tool for Learning about Technological Developments in Industrial Settings', in D. Blandow \& M. J. Dyrenfurth (eds.), Technology Education in School and Industry. Emerging Didactics for Human Resource Development, Springer Verlag, Berlin/Heidelberg.

Vries, M. J. de: 1994iii). 'Design Process Dynamics in an Experience-based Context: A Design Methodological Analysis of the Brabantia Corkscrew Development', Technovation 14(7), 437-448. 